\title{
EFFECT OF PEPTIDES SYNTHESIZED FROM LACTOFERRIN OF BUFFALO MILK ON OXIDATIVE STRESS IN KUNMING MICE
}

\author{
P. Yang ${ }^{1}$, M. Abel-Hamid ${ }^{2}$, E. Romieh ${ }^{2}$, L. Huang, Q.K.Zeng ${ }^{1}$, H.R.Nong ${ }^{1}$, L.Feng ${ }^{1}$, Y.Tang ${ }^{1}$ and L. Li ${ }^{1 *}$ \\ ${ }^{1}$ Guang Xi Buffalo Research Institute, Chinese Academy of Agricultural Sciences, Nanning 530001, PR China \\ ${ }^{2}$ Dairy Science Department, Faculty of Agriculture, Cairo University, 12613 Giza, Egypt. \\ "Corresponding author's email: lling2010@163.com \\ The paper was presented in International Buffalo Congress 2019, February 18-20, Lahore, Pakistan
}

https://doi.org/10.36899/JAPS.2020.1.0008

Published online January 02,2020

\begin{abstract}
Oxidative stress plays an important role in the pathogenesis of lifestyle-related diseases. Lactoferrin antioxidant peptide sequence SVDGKEDLIW has been purified from buffalo milk protein and then synthesized by solid phase synthesis. The antioxidant activity of the synthetic peptide was evaluated in D-Galactose treated Kunming mice. The experiment design included 35 mice that randomly divided into 5 groups named, normal group, G-Galatose model group, DGalactose + low dose of synthetic peptide $(0.1 \mathrm{~g} / \mathrm{kg}$ body weight), D-Galactose + high dose of synthetic peptide $(0.6 \mathrm{~g} / \mathrm{kg}$ body weight) and D- Galctose + vitamin C. After 6 weeks, mice were sacrificed and the activities of superoxide dismutase (SOD), glutathione peroxidase (GSH-PX) and malondialdehyde (MDA) in blood, heart, liver and brain of mice were measured. The mice group of high-dose peptide showed significantly $(P<0.01)$ higher liver index $(5.89)$ than that of D-Galactose model group (4.41). The highest SOD activity values of heart, liver, brain and blood were obtained in low-dose synthetic peptide group (212.33, 404.88, 296.26 "U/mg protein" and 28.15 "U/g protein", respectively). Similarly, low-dose synthetic peptide group showed significantly $(P<0.05)$ higher values of GSH-PX activity. Whereas, MDA contents in heart and whole blood $(0.35$ and 25.24 "nmol/mg protein", respectively) were significantly $(P<0.05)$ decreased in the low-dose peptide group. This study emphasizes the antioxidant activity of SVDGKEDLIW in vivo and demonstrates a promising antioxidant capacity of the synthetic peptide derived from lactoferrin of buffalo milk.
\end{abstract}

Key words: Synthetic peptide; D-galactose; Aging model; Antioxidant activity.

\section{INTRODUCTION}

The accumulation of reactive oxygen species (ROS) and depletion of intracellular antioxidants are hallmarks of oxidative stress (Cho et al., 2007). Oxidative stress considered as the main reason of various diseases, including cancer, aging, diabetes, anxiety, atherosclerosis, Alzheimer, rheumatoid, atherosclerosis and cardiovascular diseases (Bouayed et al., 2009 and Pihlanto, 2006). Also, excess free radicals decrease quality and the shelf-life of foods (Shazly et al., 2017). Various studies have been performed to control, prevent and/or delay oxidative stress and its deleterious effects including developing variants of synthetic and natural antioxidants. Antioxidant peptides are promising agents for increase the shelf life of foods (Hogan et al., 2009). In addition, they inhibit oxidative stress in plasma from excessive free radical production consequently reduce the risk of aging (Power-Grant et al., 2016).

Propyl gallate, butylated hydroxytoluene, tertbutylhydroquinone and butylated hydroxyanisole are synthetic antioxidants and commonly used to prevent the oxidation process in food. Although, these antioxidant are cheap but they have some disadvantage i.e. display some toxic and hazardous effects (Feng et al., 2018).
Therefore, novel natural antioxidant materials are in demand. Antioxidant peptides are relatively important categories in natural antioxidant, it is not only can remove free radicals, but also substantially contributes to body's defense, immunity, promote mineral absorption, and other functions (Hernández-Ledesma et al., 2014; Ebner et al., 2015; Nongonierma and FitzGerald, 2015).

Numerous reports demonstrated that milk proteins are not only source of essential amino acids, but also source of bioactive peptides which are specific protein fragments in the size of 2-20 amino acids (Korhonen and Pihlanto, 2006) . Hydrolysis of milk protein using proteolytic enzymes resulted in a wide range of bioactive peptide i.e. antibacterial, antioxidant anti-cancer peptide (Abdel-Hamid et al., 2016). Different antioxidant peptides were isolated from milk proteins from different species by fermentation, proteolytic enzymes, and digestive enzymes (Lorenzo et al., 2018; Abdel-Hamid et al., 2019).

Buffalo is the second global milk-producing animal all over the world and widely distributed throughout Asia. It is worth noting that more than $95.8 \%$ of the world population of water buffalo are kept in Asia (El-salam and El-shibiny, 2011). Buffalo milk has a high content of fat, protein, lactose, vitamins and minerals, and 
consequently high nutrient contents, which has attracted enormous attention by both academic researchers and dairy industry for various dairy products manufacturing (Han et al., 2007). Furthermore, it has been reported that subjects with cow milk allergies are capable of tolerating buffalo milk (El-salam and El-shibiny, 2011). Buffalo's milk protein is an important source of bioactive peptides including antioxidant, antibacterial and angiotensin converting enzymes inhibitory peptides (Nighswonger, 1996; Shanmugam et al., 2015; Abdel-Hamid et al., 2017; Taha et al., 2017).

D-galactose metabolism led to produce ROS in animals. Similar symptoms of natural aging have been reported when the animal feed an excess amount of Dgalactose for a long time. Therefore, D-galactose induced aging is a common model for aging research and oxidative stress (Peng et al., 2014). These authors reported that oral administration of low molecular weight (0.1-2.8 KDa) whey protein hydrolysates significantly improved superoxide dismutase (SOD), catalase activity and reduced malondialdehyde (MDA) content in Dgalactose induced aging rats.

In this context, buffalo's milk protein was hydrolysed by protease enzyme in other experiments conducted by our research group (Ling et al., 2018). The antioxidant activity of the buffalo's milk protein hydrolysed with flavourzyme and its RP-HPLC fractions was assessed. The most antioxidant active RP-HPLC fraction was subjected to MALDI-TOF/TOF for peptide identification. The identified peptides were synthetized. Among the synthetic peptides, SVDGKEDLIW that liberated from buffalos lactoferrin, exhibited the highest antioxidant activity in vitro. The aim of this study is to assess the antioxidant activity of the synthetic peptide SVDGKEDLIW in vivo on D-galactose induced aging mice.

\section{MATERIALS AND METHODS}

Materials: D-galactose was obtained from Sigma (USA). Superoxide dismutase (SOD), glutathione peroxidase (GSH-PX), malondialdehyde (MDA) and protein assay kits were purchased from Jiancheng Biochemical Co., Ltd. (Nanjing, China). Kunming male mice (12 week) were obtained from Animal Center of Guangxi Medical University, Nanning, China.

Peptide synthesis: Peptide SVDGKEDLIW was synthesized using solid-phase amino acid synthesizer according to Mojsoska and Jennsen (2015) at Zhejiang Ontores Biotechnologies Co. (Hangzhou, China), followed by treatment with hydrogen fluoride to cut off the support resin and to remove all of the protecting groups. The final products were purified on RP-HPLC (Waters) with a Kromasil C18 column $(5 \mu \mathrm{m}, 4.6 \times 150$ $\mathrm{mm}$, using a gradient of $\mathrm{MeCN}$ from $20 \%$ to $100 \%$ in
$0.1 \%$ TFA for $40 \mathrm{~min}$ at a flow rate of $1 \mathrm{~mL} \mathrm{~min}^{-1}$, and the elution was monitored at $220 \mathrm{~nm}$. The resultant peptide mass and purity was further checked by LC-MS with electrospray ionization (3200 QTRAP, Waters Technologies).

Animal experiment: Kunming mice were housed for 6 weeks at $24 \pm 2{ }^{\circ} \mathrm{C}$ and $12 \mathrm{~h}$ light / dark interval cycle according to the National Standard Animal Feed and given ad libitum access to food and water.

Thirty five mice were randomly divided into 5 groups, 7 in each as followed: group 1: negative control, group 2: D-galactose group, mice were injected (subcutaneous) daily by D-galactose $(500 \mathrm{mg} / \mathrm{kg}$ body) to induce aging model. Groups 3 and 4, mice were injected daily by D-galactose and at the same time orally administrated $0.1 \mathrm{~g} / \mathrm{kg}$ and $0.6 \mathrm{~g} / \mathrm{kg}$ of the synthetic peptide (low and high dose) as a suspension in $0.5 \mathrm{ml}$ water. Group 5, mice were injected daily by D-galactose and at the same time orally administrated $0.05 \mathrm{~g} / \mathrm{kg}$ of vitamin C. Negative control and D-Galactose control groups were orally administrated $0.5 \mathrm{ml}$ of physiological saline. After 6 weeks, mice were sacrificed and blood samples were collected from retro-orbital venus plexus from all animals in plain test tubes.

Blood and organs collection: After 6 weeks, mice were sacrificed and blood samples were collected from retroorbital venus plexus from all animals in plain test tubes. The whole brain, liver and heart tissue were removed and weighed immediately after mice sacrificed to calculate liver, brain, heart indexes by dividing organ weight by rat weight $\times 100$. Viscera index is the weight of brain, heart or liver dividing by weight of mice $\times 100$.

Determination of MDA, GSH-PX and SOD activities: MDA, GSH-PX and SOD activities were determined using colorimetric method according to the protocol provided by the kit manufacturer.

Organs were homogenized in phosphate buffer saline $(\mathrm{PBS})(1: 9 \mathrm{w} / \mathrm{v})$ at $1200 \mathrm{rpm}$ using homogenizer. The homogenates were centrifuged at $8000 \mathrm{x} \mathrm{g}$ for 10 minutes at $4 \circ \mathrm{C}$, and the supernatants were collected and used to measure the activity of GSH-PX, SOD and MDA contents.

Protein content: Serum and organs protein contents were measured using Bradford Protein Assay Kit (Jiancheng Biochemical Co. Ltd. Nanjing, China).

Statistical analysis: Data are presented as the mean values \pm standard deviation (SD). Data were analysed by one-way analysis of variance (ANOVA) using SPSS 20.0 statistical analysis software. Results were considered statistically significant at $\mathrm{P}<0.05$.

\section{RESULTS AND DISCUSSION}


Peptide purification and synthesis: Peptides with high antioxidant activity were isolated from buffalo milk protein hydrolysed with flavourzyme using ÄKTA pure chromatography system (GE Healthcare, Sweden) and the column used was superdex ${ }^{\mathrm{TM}}$ peptide (10/300) as described in our previous work (Ling et al., 2018). The fraction with highest antioxidant activity were collected and lyophilized. The active fraction was further fractionated by RP-HPLC (Figure 1). Among eight peaks were eluted by RP-HPLC, fraction of peak no. 7 showed the highest antioxidant activity (Figure 1). This fraction was subjected to MALDI TOF/TOF for peptide identification. The major identified peptides sequences were of FLPYPY and SVDGKEDLIW. FLPYPY was liberated from kappa casein and SVDGKEDLIW was liberated from lactoferrin. All identified peptides were synthesized then purified by RP-HPLC to assess their antioxidant (figure 2A). The yield of synthetic peptide SVDGKEDLIW after purification step was 20\%. The peptide mass was checked by LC-MS (Figure 2B).

Peptide with SVDGKEDLIW sequence showed the highest antioxidant activity. SVDGKEDLIW is lactoferrin origin peptide. It contains hydrophobic amino acids which reflect its antioxidant activity (Rajapakse et al., 2005). Also, tryptophan at the c-terminal plays an important role as an antioxidant and angiotensinconverting enzyme (ACE) inhibitory activities for this peptides. In addition, SVDGKEDLIW inhibited prolyl endopeptidase (PEP) in a Caenorhabditis elegans model of Alzheimer's disease (Manzanares et al., 2018).

Synthetic peptide SVDGKEDLIW showed the highest antioxidant activity in vitro. This finding motivated us to investigate the antioxidant activity of this peptide in vivo

Effect of oral administration of synthetic peptide on viscera index in mice: Viscera index reflects the overall nutritional status in mice and the pathological changes of organs. Viscera indexes of the mice are presented in Table 1. D-Galactose injection led to lower heart and brain indexes and higher liver index compared to the normal control group. Oral administration of synthetic peptide improved the viscera index compared to the D-Galactose control group. However, no significant differences $(P>0.05)$ in heart and brain indexes were observed between groups. These results are in agreement with those of Wang et al. (2018) who observed that oral administration of oyster protein hydrolysates had no significant differences in brain and spleen indexes compared with D-Galactose model mice. Additionally, Li et al. (2012) reported that oral administration of $L b$. plantarum strains (C88) showed no significant effect on liver, heart, and kidney indices compared with D-gal model mice $(P>0.05)$.

In contrast to brain and heart indexes, oral administration of synthetic peptide at high dose level and vitamin $\mathrm{C}$ significantly $(P<0.01)$ increased the liver index compared with D-Galactose model mice (Table 1). Oral administration of vitamin $\mathrm{E}$ increased the liver index compared with D-Galactose treated mice (Li et al., 2012).

\section{Effect of oral administration of synthetic peptide on oxidative stress}

Superoxide dismutase (SOD) content in mice tissues and whole blood: SOD is an antioxidant enzyme that plays important role in almost all organisms. It can be catalytic superoxide disproportionation for $\mathrm{H}_{2} \mathrm{O}_{2}$ and oxygen, so it is the key to the aging evaluation index. Data in Table 2 show that D-Galactose injection decreased the level of SOD in mice organs and whole blood compared with normal mice. This is due to the damage induced by D-Galactose injection caused superoxide anion-induced oxidative and led to decrease the activity of SOD (Peng et al., 2014).

Oral administration of high dose synthetic peptide significantly $(P<0.01)$ increased the SOD level in liver tissue, and non-significant increase was observed in SOD level in heart, brain and whole blood compared with D-Galactose treated mice.

It is worth noting that oral administration of low dose of synthetic peptide significantly $(P<0.01)$ increased SOD content in liver, heart and brain tissues, and non-significant $(P>0.01)$ increase was noticed in SOD level in whole blood. These results are in agreement with Li et al. (2012) who found that oral administration of $\mathrm{Lb}$. plantarum increased the level of SOD in serum of mice. Furthermore, oral administration of whey protein hydrolysates significantly increased SOD levels in the serum, spleen, liver and lung of D-Galactose treated rats as reported by Peng et al. (2014). In addition, oral administration and intraperitoneal injection of whey protein hydrolysate increased the SOD level in liver tissue of mice treated with paracetamol (Athira et al., 2013). Oral administration of milk protein hydrolysate significantly increased the SOD activity in plasma of rate treated with Alloxan (Awad et al., 2016)

In this context, it is of interest to note that the administration of synthetic peptide is effective tool in preventing the decrease of SOD activity caused by superoxide anion-induced oxidative damage induced by D-galactose.

Glutathione peroxidase (GSH-PX) content in mice tissues and whole blood: GSH-PX is an important antioxidant enzyme that plays a key role in $\mathrm{H}_{2} \mathrm{O}_{2}$ catalytic and detoxification of endogenous metabolic hydrogen peroxide and peroxide. GSH-PX considered as an indicator of body antioxidative ability status.

It is clear from the data in Table 3 that injection of D-Galactose significantly $(P<0.01)$ decreased in the activity of GSH-PX in the whole blood, brain and liver compared with normal mice and had non-significantly 
effect on GSH-PX activity in heart tissue. Decreasing of GSH-PX activity by D-Galactose could due to one of the following reasons: 1) D-Galactose led to free radical accumulation which cause inactivation of GSH-PX; 2) consumption of GSH-PX co-substrates GSH and NADPH (Peng et al., 2014). Similarly, a decline in GSHPX activity after treated by D-Galactose was observed by Kumar et al. (2011) and Peng et al. (2014).

In comparison to the D-Galactose model group, oral administration of low dose synthetic peptide significantly $(P<0.05)$ increased GSH-PX activity in liver, heart, brain and whole blood. Whereas, the oral administration of high dose synthetic peptide significantly $(P<0.01)$ increased the GSH-PX activity in heart and brain tissues and no significant $(P>0.01)$ effect was found in GSH-PX activity in liver and whole blood. These results are in line with Peng et al. (2014) and Wang et al. (2018) who reported that oral administrations of whey protein hydrolysates and oyster protein hydrolysates have significantly increased the activity of GSH-PX in tissues and serum in D-galactose model. In this context, Hamad et al. (2011) reported higher GSHPX activity in rat after oral administration of whey protein hydrolysate compared to unhydrolysed whey protein. Furthermore, Athira et al. (2013) concluded that intraperitoneal injection of whey protein hydrolysates increased the GSH-PX activity in liver tissue of mice treated with paracetamol. Oral administration of milk protein hydrolysate significantly improved the activity of GSH-PX in rat treated with alloxan (Awad et al., 2016).
Malondialdehyde (MDA) content in mice tissues and whole blood: MDA is one of the end products in the lipid peroxidation. MDA content considered as an indicator of oxidative stress. MDA level (nmol/mg protein) in tissues and whole blood are given in Table 4 . The results showed that D-Galactose model group had higher MDA content in tissue and whole blood compared with normal group. Accumulation of free radicals as a result of D-Galactose injection lead to lipid peroxidation, and then MDA concentration will increase (Peng et al., 2014; Wang et al., 2018).

The oral administration of high dose synthetic peptide has shown no significant $(P>0.05)$ influence on MDA level in tissues and whole blood. In contrast, oral administration of low dose synthetic peptide was significantly decreased MDA content in the whole blood and heart compared with D-Galactose model group $(P<$ $0.05)$. it has been reported that oral administration of whey protein hydrolysates significantly decreased the concentration of MDA in tissues and serum in Dgalactose model (Peng et al., 2014). Additionally, oral administration of oyster protein hydrolysates significantly $(P<0.05)$ reduced the level of MDA in mice with oxidative stress. Oral administration of the antioxidant peptide inhibited the accumulation of free radicals that led to decrease of the MDA level compared with DGalactose group. Hamad et al. (2011) reported that serum MDA level decreased after oral administration of whey protein hydrolysate in rat fed high carbohydrate free fat diet.

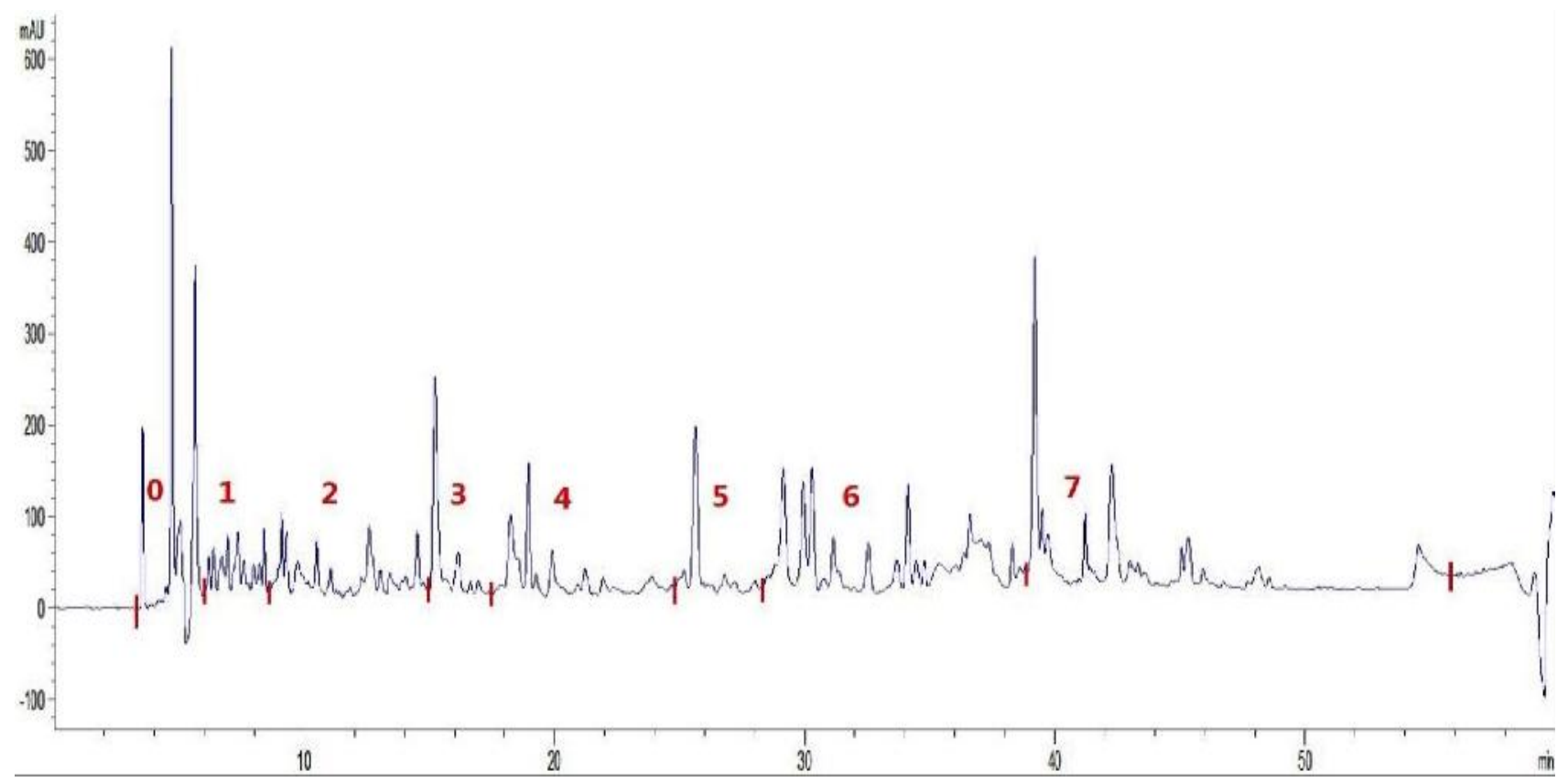

Figure 1. Fractionation of buffalo's milk protein hydrolysate using RP-HPLC. 0, 1, 2...7 are the fractions numbers. 


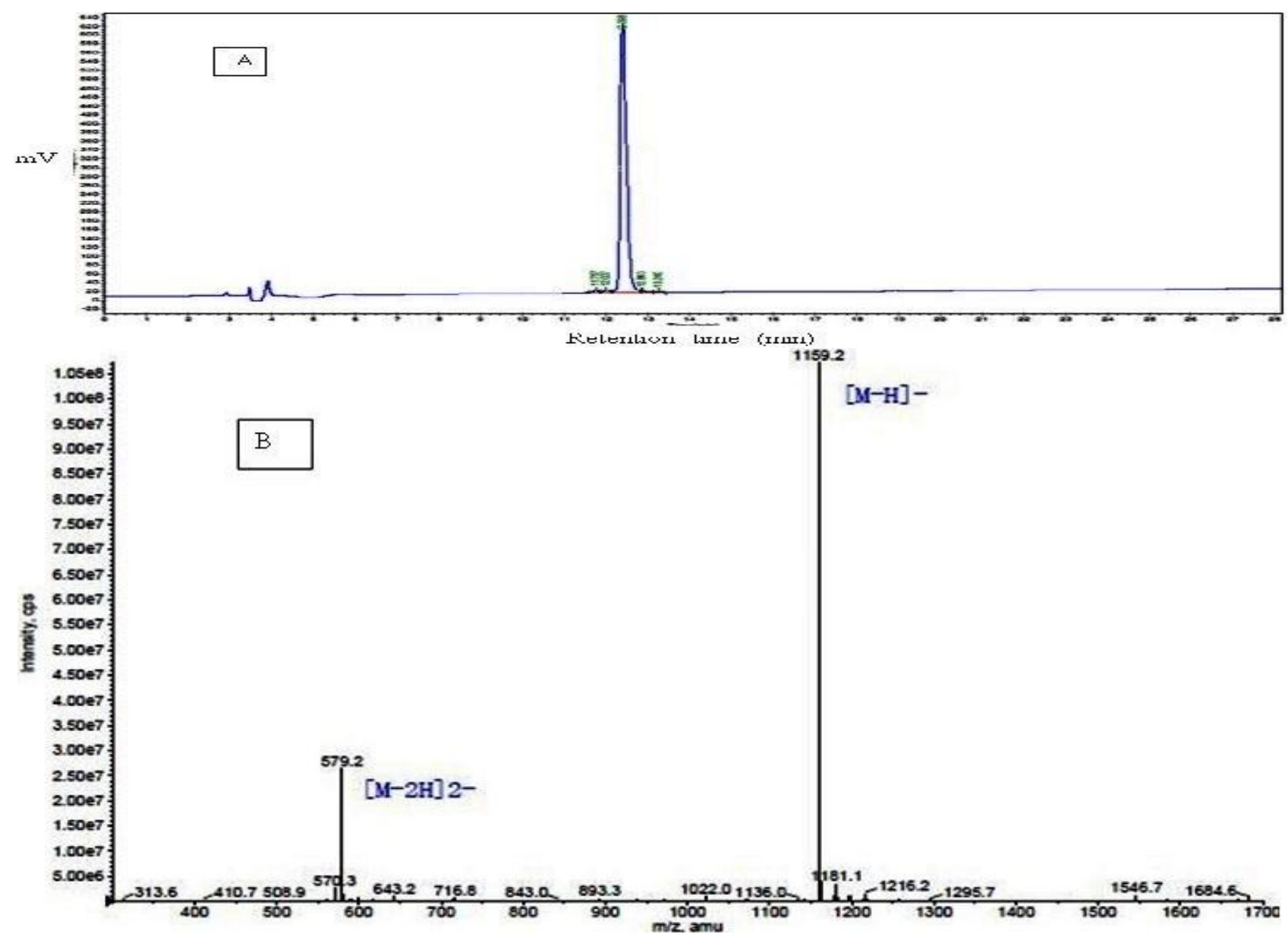

Figure 2. Purification of synthetic peptide by RP-HPLC (A) and mass confirmation by LC MS (B)

Table1. Effect of oral administration of synthetic peptide on viscera index ${ }^{\mathrm{a}}$ in mice.

\begin{tabular}{cccc}
\hline Group & Liver index & heart index & brain index \\
\hline Normal group & $4.07 \pm 0.47$ & $0.45 \pm 0.03$ & $1.12 \pm 0.39$ \\
D-Galactose model group & $4.41 \pm 0.30$ & $0.43 \pm 0.05$ & $1.05 \pm 0.12$ \\
Positive drug group (vitamin C) & $5.16 \pm 0.81^{* *}$ & $0.47 \pm 0.09$ & $1.09 \pm 0.18$ \\
High dose synthetic peptide group & $5.89 \pm 0.43^{* *}$ & $0.45 \pm 0.06$ & $1.13 \pm 0.17$ \\
Low dose synthetic peptide group & $4.69 \pm 0.22$ & $0.46 \pm 0.03$ & $1.17 \pm 0.10$ \\
\hline
\end{tabular}

Data are means \pm standard deviation $(n=7)$

"Viscera index is the weight of brain, heart or liver /weight of mice $\times 100$

${ }^{* *}$ Indicating a significant difference $(P<0.01)$ with the D-Galactose model group.

Table 2. Effect of oral administration of synthetic peptide on superoxide dismutase (SOD) level in whole blood and organs.

\begin{tabular}{ccccc}
\hline Group & $\begin{array}{c}\text { Liver } \\
\text { (U/mg protein) }\end{array}$ & $\begin{array}{c}\text { Heart } \\
\text { (U/mg protein) }\end{array}$ & $\begin{array}{c}\text { Brain } \\
\text { (U/mg protein) }\end{array}$ & $\begin{array}{c}\text { Whole blood } \\
\text { (U/g protein) }\end{array}$ \\
\hline Normal group & $304.86 \pm 23.97$ & $178.96 \pm 9.20$ & $252.52 \pm 34.17$ & $25.43 \pm 3.7$ \\
D-Galactose model group & $291.28 \pm 42.11$ & $162.75 \pm 16.36$ & $251.97 \pm 32.21$ & $24.15 \pm 4.9$ \\
Positive drug group (vitamin C) & $318.66 \pm 25.35$ & $211.78 \pm 22.98^{* *}$ & $253.55 \pm 54.76$ & $26.30 \pm 6.6$ \\
High dose synthetic peptide group & $363.48 \pm 51.37^{* *}$ & $173.05 \pm 15.65$ & $279.57 \pm 30.02$ & $27.96 \pm 5.1$ \\
Low dose polypeptide group & $404.88 \pm 49.33^{* *}$ & $212.33 \pm 14.36^{* *}$ & $296.26 \pm 26.58^{*}$ & $28.15 \pm 5.8$ \\
\hline
\end{tabular}

Data are means \pm standard deviation $(\mathrm{n}=7)$

${ }^{*}$ Indicating a significant difference $(P<0.05)$ and ${ }^{* *}$ indicating a significant difference $(P<0.01)$ with the D-Galactose model group. 
Table 3. GSH - PX content (Energy unit) in mice tissues and whole blood.

\begin{tabular}{cllll}
\hline Group & \multicolumn{1}{c}{ Liver } & \multicolumn{1}{c}{ Heart } & \multicolumn{1}{c}{ Brain } & \multicolumn{1}{c}{ Whole blood } \\
\hline Normal group & $203.99 \pm 8.42^{* *}$ & $33.10 \pm 3.15$ & $14.66 \pm 1.76^{* *}$ & $441.09 \pm 28.35^{* *}$ \\
D-Galactose model group & $147.45 \pm 37.99$ & $31.82 \pm 3.65$ & $11.57 \pm 1.04$ & $339.68 \pm 39.35$ \\
Positive drug group (vitamin C) & $210.28 \pm 33.46^{* *}$ & $50.63 \pm 8.00^{* *}$ & $13.68 \pm 1.01^{*}$ & $425.04 \pm 76.55^{* *}$ \\
High dose synthetic peptide group & $150.51 \pm 29.05$ & $47.08 \pm 7.17^{* *}$ & $15.35 \pm 1.90^{* *}$ & $334.48 \pm 38.97$ \\
Low dose polypeptide group & $242.09 \pm 45.82^{* *}$ & $53.02 \pm 8.22^{* *}$ & $17.22 \pm 3.47^{* *}$ & $402.02 \pm 46.89^{*}$ \\
\hline
\end{tabular}

Data are means \pm standard deviation $(\mathrm{n}=7)$

${ }^{*}$ Indicating a significant difference $(P<0.05)$ and ${ }^{* *}$ indicating a significant difference $(P<0.01)$ with the D-Galactose model group.

Table 4. MDA content (nmol/mg protein) in mice tissues and whole blood.

\begin{tabular}{lcccc}
\hline Group & Liver & Heart & Brain & Whole blood \\
\hline Normal group & $0.11 \pm 0.02^{*}$ & $0.63 \pm 0.34$ & $2.81 \pm 0.39$ & $41.35 \pm 15.54$ \\
D-Galactose model group & $0.15 \pm 0.03$ & $0.69 \pm 0.36$ & $3.09 \pm 0.77$ & $46.63 \pm 14.30$ \\
Positive drug group (vitamin C) & $0.17 \pm 0.07$ & $0.58 \pm 0.14$ & $3.28 \pm 0.80$ & $39.13 \pm 13.32$ \\
High dose synthetic peptide group & $0.16 \pm 0.02$ & $0.88 \pm 0.15$ & $3.41 \pm 0.64$ & $41.28 \pm 9.96$ \\
Low dose polypeptide group & $0.15 \pm 0.04$ & $0.35 \pm 0.18^{*}$ & $2.97 \pm 0.31$ & $25.24 \pm 5.53^{*}$ \\
\hline
\end{tabular}

Data are means \pm standard deviation $(\mathrm{n}=7)$

${ }^{*}$ Indicating a significant difference $(P<0.05)$ with the D-Galactose model group.

Conclusion: This study demonstrated the utilization of synthetic peptide (SVDGKEDLIW) derived from buffalo's lactoferrin as a potential antioxidant agent in DGalactose treated mice. Oral administration of synthetic peptide improved viscera index of D-Galactose treated mice compared with D-Gal model mice. Furthermore, oral administration of synthetic peptide markedly increased the activity of the antioxidant enzymes (SOD and GSH-PX) in liver, heart, brain and whole blood compared with D-Gal model. In addition, oral administration of synthetic peptide significantly decreased the content of MDA in heart tissue and whole blood compared with D-Gal model. Oral administration of synthetic peptide has proven to have antioxidant activities in vivo and appeared to have potential as a valuable alternative to control free radicals and activate the antioxidant enzymes.

Acknowledgment: This study was supported by the Guangxi Key Research and Development Program (Guangxi science AB1850017).

\section{REFERENCES}

Abdel-Hamid, M., H. A. Goda, C. De Gobba, H. Jenssen, and A. Osman, (2016). Antibacterial activity of papain hydrolysed camel whey and its fractions. Int Dairy J. 61: 91-98.

Abdel-Hamid, M., J. Otte, C. De Gobba, A. Osman, and E. Hamad (2017). Angiotensin I-converting enzyme inhibitory activity and antioxidant capacity of bioactive peptides derived from enzymatic hydrolysis of buffalo milk proteins. Int Dairy J. 66: 91-98.
Abdel-Hamid, M., E. Romeih, R. R. Gamba, E. Nagai, T. Suzuki, T. Koyanagi, and T. Enomoto (2019). The biological activity of fermented milk produced by Lactobacillus casei ATCC 393 during cold storage. Int Dairy J. 91: 1-8.

Athira, S., B. Mann, R. Sharma, and R. Kumar (2013) Ameliorative potential of whey protein hydrolysate. against paracetamol-induced oxidative stress. J. Dairy Sci. 96 (3): 1431-1437.

Awad, S., A. Wahba, A. El Attar, M. I. Yousef, and M. Zedan (2016). Antioxidant activity of milk protein hydrolysate in alloxan-induced diabetic rats. J. Dairy Sci. 99 (11): 8499-8510.

Bouayed, J., H. Rammal, and R. Soulimani (2009). Oxidative stress and anxiety: Relationship and cellular pathways a link between oxidative stress metabolic pathways and anxiety-related phenotypes. Oxid Med. Cell Longev. 2(2): 63-67.

Cho, S., H. H. Szeto, E. Kim, H. Kim, A. T. Tolhurst, and J. T. Pinto (2007). A novel cell-permeable antioxidant peptide, SS31, attenuates ischemic brain injury by down-regulating CD36. J. Bio Chem. 282 (7): 4634-4642.

Ebner, J., A. Aşçi Arslan, M. Fedorova,R. Hoffmann, A. Küçükçetin, and M. Pischetsrieder (2015). Peptide profiling of bovine kefir reveals 236 unique peptides released from caseins during its production by starter culture or kefir grains. J. Proteomics 117: 41-57.

El-salam, M. H. A., and S. El-shibiny (2011). A comprehensive review on the composition and properties of buffalo milk. Dairy Sci. and Technol. 91: 663-699.

Feng, Y., G. Ruan, F. Jin, J. Xu, and F. Wang (2018). 
Purification, identification, and synthesis of five novel antioxidant peptides from Chinese chestnut (Castanea mollissima Blume) protein hydrolysates. LWT - Food Sci. Technology 92: 40-46.

Hamad, E. M., S. H. Taha, A. I. Abou Dawood, M. Z. Sitohy, and M. Abdel-Hamid (2011). Protective effect of whey proteins against nonalcoholic fatty liver in rats. Lipid Health Dis. 10: 57.

Han, B., Y. Meng, M. Li, Y. Yang, F. Ren, Q. Zeng, and M. J. R. Nout (2007). A survey on the microbiological and chemical composition of buffalo milk in China. Food Control 18 (6): 742746.

Hernández-Ledesma, B., M. J. García-Nebot, S. Fernández-Tomé, L. Amigo, and I. Recio (2014). Dairy protein hydrolysates: Peptides for health benefits. Int Dairy J. 38(2): 82-100.

Hogan, S., L. Zhang, J. Li, H. Wang, and K. Zhou (2009). Development of antioxidant rich peptides from milk protein by microbial proteases and analysis of their effects on lipid peroxidation in cooked beef. Food Chem. 117(3): 438-443.

Korhonen, H., and A. Pihlanto (2006). Bioactive peptides : Production and functionality. Int Dairy J. 16: 945-960.

Kumar, A., A. Prakash, and S. Dogra (2011). Protective effect of curcumin (Curcuma longa) against dgalactose-induced senescence in mice. J. Asian Nat Prod Res. 13(1): 42-55.

Li, S., Y. Zhao, L. Zhang, X. Zhang, L. Huang, D. Li, and Q. Wang (2012). Antioxidant activity of Lactobacillus plantarum strains isolated from traditional Chinese fermented foods. Food Chem. 135(3): 1914-1919.

Ling, L., P. Yang, Z. Qing-Kun, H. Li, T. Yan, N. Hao-Ru, and F. Ling (2018). A buffalo milk antioxidant peptide and its separation and preparation method. Patent no 201810310855.2. China.

Lorenzo, J. M., P. E. S. Munekata, B. Gómez, F. J. Barba, L. Mora, C. Pérez-Santaescolástica, and F. Toldrá, (2018). Bioactive peptides as natural antioxidants in food products - A review. Trends Food Sci. Tech. 79: 136-147.

Manzanares, P., R. Mart, S. Garrigues, S. Genov, D. Ram, J. F. M. Id, and P. Martorell (2018). Tryptophancontaining dual neuroprotective peptides: prolyl endopeptidase inhibition and caenorhabditis elegans protection from $\beta$-amyloid peptide toxicity. Int J. Mol Sci. 19:1-18.

Mojsoska, B., and H. Jenssen (2015). Peptides and peptidomimetics for antimicrobial drug design. Pharmaceuticals 8(3), 366-415.

Nighswonger, B. D. (1996). Viability of lactobacillus acidophilus and lactobacillus casei in fermented milk products during refrigerated storage. J. Dairy Sci. 79(2): 212-219.

Nongonierma, A. B., and R. J. FitzGerald (2015). Bioactive properties of milk proteins in humans. Peptides 73: 20-34.

Peng, X., B. Kong, H. Yu, and X. Diao (2014). Protective effect of whey protein hydrolysates against oxidative stress in D-galactose-induced ageing rats. Int. Dairy J. 34(1): 80-85.

Pihlanto, A. (2006). Antioxidative peptides derived from milk proteins. Int Dairy J.16: 1306-1314.

Power-Grant, O.,W. G. McCormack, M. Ramia De Cap, M. Amigo-Benavent, R. J. Fitzgerald, and P. Jakeman (2016). Evaluation of the antioxidant capacity of a milk protein matrix in vitro and in vivo in women aged 50-70 years. Int J.Food Sci. Nutr. 67(3): 325-334.

Rajapakse, N., E. Mendis, W. K. Jung, J. Y. Je, and S. K. Kim (2005). Purification of a radical scavenging peptide from fermented mussel sauce and its antioxidant properties. Food Res Int. 38(2): 175182.

Shanmugam, V. P., S. Kapila, T. K. Sonfack, and R. Kapila (2015). Antioxidative peptide derived from enzymatic digestion of buffalo casein. Int. Dairy J.42: $1-5$.

Shazly, A. B., Z. He, M. A. El-aziz, M. Zeng, S. Zhang, F. Qin, and J. Chen (2017). Fractionation and identification of novel antioxidant peptides from buffalo and bovine casein hydrolysates. Food Chem. 232:753-762.

Taha, S., M. El Abd, C. De Gobba, M. Abdel-Hamid, E. Khalil, and D. Hassan (2017). Antioxidant and antibacterial activities of bioactive peptides in buffalo's yoghurt fermented with different starter cultures. Food Sci Biotechnol. 26(5): 1325-1332.

Wang, X., H. Yu, R. Xing, S. Liu, X. Chen, and P. Li (2018). Effect and mechanism of oyster hydrolytic peptides on spatial learning and memory in mice. RSC Advances 8: 6125-6135. 